\title{
Article
}

\section{The Oslo University Adolescent and Young Adult Twin Project: Recruitment and Attrition}

\author{
Svenn Torgersen and Trine Waaktaar \\ Department of Psychology, University of Oslo, Oslo, Norway
}

\begin{abstract}
The Oslo University Adolescent and Young Adult Twin Project started in 2006 with the first of three questionnaire data collection waves, 2 years apart. All twins from the birth cohorts 1988-1994 were invited to participate, and both the twins and their parents were asked to sign consent forms. The twins were 12-18 years old at Wave 1, at which time parents were asked to complete similar questionnaires. The parents' questionnaire enquired about the parents' ratings of their twin's traits. In addition, the parents answered questions regarding their own education, demographics and socioeconomic situation. When the twins were 18 years old, they were invited to a face-to-face interview and two new questionnaires were presented. The questionnaires for the waves included a number of personality scales, internalization and externalization traits, affective and behavioral problems, as well as measures of environment and coping. The most common DSM-IV mental disorders and all personality disorders were covered in the interview. Zygosity was established both by questionnaire and gene markers. The original sample consisted of 5374 twin families, and among these, 4668 pairs were alive and living in Norway. Of these, 2486 families (53.3\%) consented to participate. Of these, again 1538 twin families (61.9\%) actually participated in at least one wave and twins from 1422 pairs (57.3\%) participated in the interview. Female gender, but not zygosity, predicted staying in the project. Moreover, having a planning, structured personality (being more conscientious, open to experience [i.e., curious and interested in learning], having higher resilience and better school habits) increased the chance of carrying on in the project. Interestingly, the attrition did not seem to bias the heritability estimates.
\end{abstract}

Keywords: Twins; sample recruitment; attrition; personality; Big Five; HIPIC; DSM-IV clinical conditions; personality disorders

(Received 30 May 2019; accepted 4 July 2019; First Published online 8 August 2019)

In 1994, the Norwegian government called for a proposal of a research project in the area of resilience among youth. The project named 'Resilient Future' won the competition. The aim of the project was to study the causes and consequences of resilience in youth. To study the developmental process of resilience and its interaction with adversities, behavioral adjustment and mental disorders, one has to include the role of genes. For this task, a genetically informative sample was needed. By means of behavior genetic models, one may be able to figure out the basis of the association between all these variables, especially regarding the disentanglement of apparently environmental causation from geneenvironment correlations.

Consequently, the work started out by collecting a twin sample of adolescents. The intention was to follow the sample at least through youth and early adulthood to figure out causal relationships.

\section{Sample Recruitment}

After a year of obtaining the necessary permissions, a list of more than 5374 twin pairs were assembled from the countrywide Norwegian Birth Register. The twins were born in the years 1988-1994, seven cohorts who were between 12 and 18 years in

Author for correspondence: Svenn Torgersen, Email: svennt@uio.no

Cite this article: Torgersen S and Waaktaar T. (2019) The Oslo University Adolescent and Young Adult Twin Project: Recruitment and Attrition. Twin Research and Human Genetics 22: 641-646, https://doi.org/10.1017/thg.2019.51
2006 when the start of data collection was planned. The planned procedure was to administer questionnaires in three waves, 2 years apart, and a face-to-face interview when the twins reached 18 years. At the time of the interview, the twins also received a self-report questionnaire of the Big Five, together with a questionnaire about affective, cognitive and behavioral reactions to sensitive interpersonal situations.

It transpired that one or both twins had died in 475 twin pairs (see Figure 1). Furthermore, 131 families had moved abroad. The address was unknown for 100 families, reducing the total number of actual twin families to 4668 . The families were contacted by mail, informed about the study's goals and procedures and invited to participate. In 2486 families, either one or both of the parents or one or both of the twins consented to participate, corresponding to $50.8 \%$ of the 5374 families with living twins retrieved from the Birth Registry, and $53.3 \%$ of the 4668 families living in Norway with a known address. In 1976 families, both parents and both twins consented to participate. (The reason for incomplete consent from family members was death of the father in 98 families, death of the mother in three families, and death of both parents in one family. Moreover, 360 fathers, 40 mothers, and one or both twins from eight families declined to participate.)

In the original twin cohorts, $51.0 \%$ were boys. After excluding families because of twin death, the percentage of boys was reduced to 50.6 , to $50.5 \%$ after excluding families that had moved abroad and to $50.3 \%$ because of unknown address. Lack of consent further reduced the boys' percentage to 46.7 . 


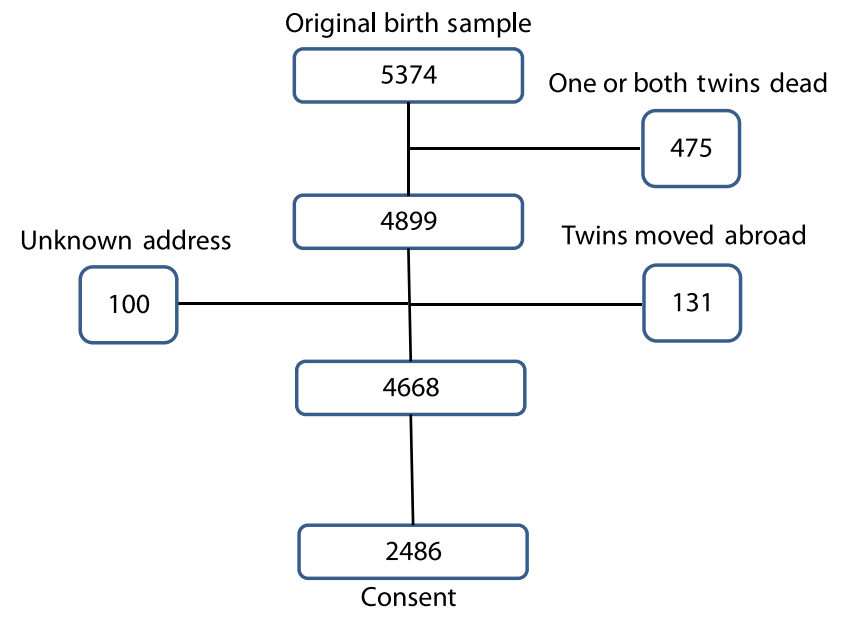

Fig. 1. Attrition of twin pairs from birth to consent.

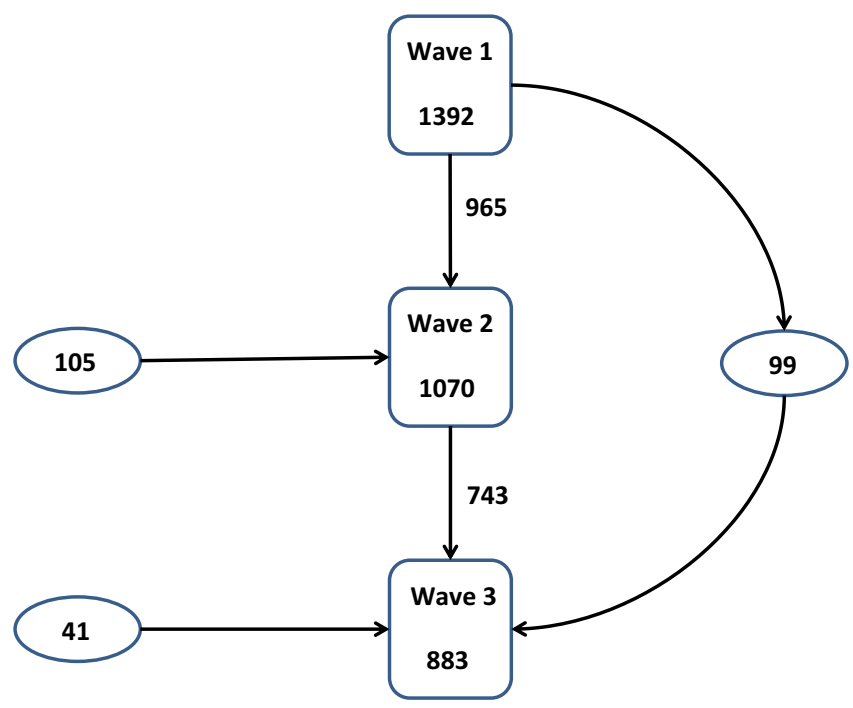

Fig. 2. Attrition through the waves.

\section{Research Design}

The research plan required that both mothers and fathers completed separate questionnaires about each twin. In addition, the twins themselves were asked to fill in questionnaires three times, at ages $12-18,14-20$ and 16-22. The twins only gave a face-to-face interview at around age 18, or later if they were hard to locate. The first wave of the questionnaire data collection was supposed to take place in 2006, the second in 2008 and the third in 2010. The interviews had started already in 2006 when the first cohort (1988) was 18 years old. In 2012, the interviews with the youngest (1994) cohort, who then turned 18 years, could finally begin.

\section{Questionnaires}

The questionnaires were almost completely identical for all informants at all waves. The exception was questions about demographics from the parents and questions about sexual topics for the twins. In order to maximize the number of scales, only a few items were included for each. These were retrieved from the results of a pilot study that had been performed previously with the complete scales. From the complete scales, items producing similarly high item-to-trait correlations in both sexes and across all age groups were selected. As the project's original focus was reactions to adversities, the questionnaire included a number of common, more or less stressful life events, and also a few positive events; (Masten, Neemann, \& Andenas, 1994). The parenting style was included, focusing on liberal, authoritarian and laissez-faire styles, as seen from the parental as well as the twin's point of view (Reitman et al., 2001). Central in the questionnaire were two resilience trait scales, a so-called 'ego-resilience' scale (Block \& Kremen, 1996), and another scale simply called 'Resilience scale' (RS; Wagnild \& Young 1993). In addition, several other personality scales were included: a Big Five scale for children and youth, named the Hierarchical Inventory for Personality in Children (HiPiC; Mervielde \& De Fruyt, 1999) and other scales covering a broad array of personality traits, namely, self-efficacy, including social aptitudes, good school work habits and law-abiding behavior (Pastorelli et al., 2001). Internalizing (or internalizing-reversed) scales used were Sense of Coherence (Antonovsky, 1987; Mehlum, 1998), loneliness (Russel, Peplau, \& Cutrona, 1980) and happiness (Cantril's Ladder; Cantril, 1965). Externalizing scales were delinquency (LeBlanc \& Tremblay, 1988; Tremblay et al., 1994), which comprised truancy, vandalism, violence and antisociality; the Externalizing scale of the Strength and Difficulties questionnaire (SDQ; Goodman, 1997, 2001); and Impulsivity (Patrick, Curtin, \& Tellegen, 2002). Internalizing and externalizing scales covering DSM-IV-oriented mental disorders were also included: for internalizing problems, the Depression Scale (Fendrich, Weissmann, \& Warner, 1990; Radloff, 1977); for anxiety, the Screen for Child Anxiety Related Emotional Disorders (SCARED; Birmaher et al., 1997); a scale for somatoform traits (Garber, Walker, \& Zeman, 1991) and the Eating Disorder Inventory (EDI; Garner \& Olmstedt, 1984). On the externalizing side were substance problems, smoking, alcohol and drugs (Johnston et al., 2005; Knight et al., 2002). In addition, there was a coping scale (Spirito et al., 1988) and questions about puberty development and sexuality (Petersen et al., 1988). Further questions addressed feelings of being integrated in society, school and the family (California Department of Education, 2003), as well as religious affiliation, the 'Religious Attitudes scale' (Donovan \& Jessor, 1985; Heath et al., 1999).

\section{Interview}

The interview - our outcome measure - comprised the International Neuropsychiatric Interview (MINI), an assessment of the most common Axis I disorders in the DSM-IV (Lecruiber et al., 1997; Sheehan et al., 1997, 1998). Furthermore, personality disorders were assessed by means of the Structured Interview for DSM-IV Personality Disorders (SIDP-IV; Helgeland, Kjelsberg, \& Torgersen, 2005; Helgeland \& Torgersen, 2004; Pfohl, Blum, \& Zimmerman, 1997; Torgersen, Kringlen, \& Cramer, 2001). In addition, a retrospective trauma interview was included (Fink et al., 1995). Moreover, questions addressing zygosity again, as well as general wellbeing, were posed. Moreover, the twins received two questionnaires and were asked to return them by mail: The Big Five questionnaire, NEO-PI-R (Costa \& McCrae, 1992; Martinsen, Nordvik, \& Østbø, 2005) and the Situational Signature Questionnaire (SiSiQ) for the assessment of affective, cognitive and behavioral reactions to difficult interpersonal situations (Lenswelt-Mulders \& Hettema, 2001). 
Table 1. Number of twin pairs in different wave participation combinations

\begin{tabular}{|c|c|c|c|c|c|}
\hline \multirow[b]{2}{*}{ Number of Wave Participation } & \multirow[b]{2}{*}{ Type of Wave Participation } & \multicolumn{4}{|c|}{ Pairs in: } \\
\hline & & 1 & 2 & 3 & Combination of Waves \\
\hline \multirow{2}{*}{1} & Wave 2 only & $x$ & 59 & $x$ & \multirow{2}{*}{428} \\
\hline & Wave 3 only & $x$ & $x$ & 41 & \\
\hline \multirow{2}{*}{2} & Waves 1 and 3 & 99 & $x$ & 99 & \multirow{2}{*}{413} \\
\hline & Waves 2 and 3 & $x$ & 46 & 46 & \\
\hline \multirow[t]{2}{*}{3} & All Waves & 697 & 697 & 697 & 697 \\
\hline & Total & 1392 & 1070 & 883 & 1538 \\
\hline
\end{tabular}

\section{Determination of Zygosity}

Determination of zygosity is important in all twin studies. A zygosity scale was included in the questionnaires for twins and parents (Torgersen, 1979), together with questions about how much the twins were together. To validate the assessment, a subgroup of same-sex twin pairs was asked to provide a salivary sample, which was analyzed for 17 gene markers. These 17 gene markers have a likelihood of misclassifying a dizygotic (DZ) twin pair as monozygotic (MZ) of only $p<.0001$. Twin pairs with zygosity scores in the middle between those supposed to be either $\mathrm{MZ}$ or $\mathrm{DZ}$ were oversampled. The same-sex twin pairs who were not gene tested were classified as $\mathrm{MZ}$ or DZ twins based on discriminant analysis of the zygosity scores.

\section{Attrition of Waves}

Twins as well as parents were asked to fill out questionnaires at each wave. However, if the twins passed the age of 18, parents no longer received questionnaires because most young adults leave home at this age. This means that for the youngest 1992-1994 cohorts, questionnaires were sent to both twins and parents at all three waves. However, for the cohorts 1990-1991, the parents' questionnaires were not included at Wave 3, and for the cohorts 1988-1989, the parents' questionnaires were not included at Waves 2 and 3.

When one or both, almost always both, twins returned questionnaires to us, $97.3 \%$ of the mothers and $69.6 \%$ of the fathers also filled out the questionnaires.

Figure 2 shows the reduction in participation from Wave 1 to Wave 2 and from Wave 2 to Wave 3. Participation was counted if at least one person from each family returned the questionnaire.

Thirty-one percent of twin pairs did not transit directly from one wave to the next, which was the same from Wave 1 to Wave 2 as from Wave 2 to Wave 3. Furthermore, 105 twin pairs appeared for the first time in Wave 2 and 41 pairs appeared for the first time in Wave 3. Finally, 99 pairs who participated in Wave 1, but not Wave 2, reappeared in Wave 3 .

Table 1 gives a more complete picture of the combinations of participation in the different waves. In total, 1538 pairs participated in any wave, a little more than one-fourth participated in only one wave (428 pairs), or in two waves (413 pairs), and a little less than half in all three waves (697).
Understandably, few twins appeared for the first time in Wave 2 $(59+46$ pairs), and even fewer for the first time in Wave 3 (41 pairs). The practice of inviting families that had consented, but not participated in a preceding wave, increased the number of pair/wave participations by 291 .

Table 2 shows the distribution of sex-zygosity combinations in the three waves and among those who participated in one, two or three waves. No differences between the various waves and between the numbers of participants at each wave were statistically significant in cross-tabulations. Generally, more female than male pairs participated, especially from $\mathrm{MZ}$ pairs, and slightly more same-sex DZ pairs than opposite-sex pairs participated. The percentages of males declined from 45.0 in Wave 1, through 43.3 in Wave 2 and 41.7 in Wave 3. The percentages of males were 45.0 among those who only participated in one wave, 43.3 among those who participated in two waves and 42.0 among those who participated in all three waves. We observed a tendency of females being more inclined to stay in the project. It was mentioned that in the consenting sample, the percentage of boys was 46.7. In comparison, the percentage of boys that actually participated in at least one wave was 44.5 .

The percentages of MZ twins who participated were around 3640 in different waves and among those that participated in one, two or three waves, without any difference from first to last wave or from participating in one or three waves. The total MZ percentage was $37.3 \%$.

As mentioned earlier, the plan was to carry out a wave every second year and an interview when the twins turned 18 years. This meant that the twins would be $12-18$ years old at Wave 1, 14-20 years at Wave 2 and 16-22 years old at Wave 3. The average ages of the twins in Table 3 show that slightly less than 2 years passed between Waves 1 and 2 and somewhat more than 2 years passed between Waves 2 and 3. There were up to 3 years' variation in age in the same cohort and wave, as some twins were born earlier in the cohort year, some had moved and time passed in finding the new address, and some twin families delayed for a long time before they returned the questionnaire, after being reminded the permitted number of times.

Personality differences between the twins who participated only once versus two or three times were analyzed. To investigate this, we constructed personality factors that comprised all personality scales described earlier, completed in all waves and by all informants. A three-factor solution displayed a Shyness factor with 
Table 2. Number (\%) of twin pairs participated in different data collection waves and those participated in one, two or three waves by sex and zygosity

\begin{tabular}{|c|c|c|c|c|c|c|c|c|c|c|c|c|}
\hline \multirow[b]{2}{*}{ Wave } & \multicolumn{2}{|c|}{ MMZ } & \multicolumn{2}{|c|}{$\mathrm{FMZ}$} & \multicolumn{2}{|c|}{ MDZ } & \multicolumn{2}{|c|}{ FDZ } & \multicolumn{2}{|c|}{ ODZ } & \multicolumn{2}{|c|}{ SUM } \\
\hline & $n$ & $\%$ & $n$ & $\%$ & $n$ & $\%$ & $n$ & $\%$ & $n$ & $\%$ & $n$ & $\%$ \\
\hline Wave 1 & 213 & 15.3 & 307 & 22.1 & 211 & 15.2 & 256 & 18.4 & 405 & 29.1 & 1392 & 100.0 \\
\hline Wave 2 & 148 & 13.8 & 244 & 22.8 & 151 & 14.1 & 199 & 18.6 & 328 & 30.7 & 1070 & 100.0 \\
\hline Wave 3 & 120 & 13.6 & 210 & 23.8 & 119 & 13.5 & 175 & 19.8 & 259 & 29.3 & 883 & 100.0 \\
\hline One wave & 70 & 16.4 & 86 & 20.1 & 63 & 14.7 & 70 & 16.4 & 139 & 32.5 & 428 & 100.0 \\
\hline Two waves & 69 & 16.7 & 96 & 23.2 & 68 & 16.5 & 76 & 18.4 & 104 & 25.2 & 413 & 100.0 \\
\hline Three waves & 91 & 13.1 & 161 & 23.1 & 94 & 13.5 & 136 & 19.5 & 215 & 30.8 & 697 & 100.0 \\
\hline Any wave & 230 & 15.0 & 343 & 22.3 & 225 & 14.6 & 282 & 18.3 & 458 & 29.8 & 1538 & 100.0 \\
\hline
\end{tabular}

Note: $M M Z=$ male monozygotic, $F M Z=$ female monozygotic, $M D Z=$ male dizygotic, FDZ = female dizygotic, ODZ = opposite-sex dizygotic.

Table 3. Mean $(S D)$ age of twins in each birth cohort by wave

\begin{tabular}{lccc}
\hline Birth cohort & First wave & Second wave & Third wave \\
\hline 1988 & $18.7(.49)$ & $20.8(.31)$ & $23.0(.30)$ \\
\hline 1989 & $17.6(.44)$ & $19.9(.35)$ & $22.0(.31)$ \\
\hline 1990 & $16.6(.39)$ & $18.4(.32)$ & $21.0(.30)$ \\
\hline 1991 & $15.6(.39)$ & $17.3(.31)$ & $20.0(.31)$ \\
\hline 1992 & $14.6(.39)$ & $16.4(.31)$ & $19.0(.31)$ \\
\hline 1993 & $13.6(.34)$ & $15.4(.30)$ & $18.0(.29)$ \\
\hline 1994 & $12.6(.39)$ & $14.4(.32)$ & $16.9(.32)$ \\
\hline Total & $15.2(1.97)$ & $16.9(1.97)$ & $19.6(1.95)$ \\
\hline
\end{tabular}

Note: First wave $=2006-2007$, second wave $=2008-2009$, third wave $=2010-2011$.

neuroticism, introversion and loneliness first and foremost; a Conduct Problems factor consisting of nonagreeableness, delinquency and antisociality; and a Structure factor that included conscientiousness, good school habits, openness and resilience. The Shyness factor was not related to the frequency of the participation in the data collection waves. The scores on the Conduct Problems factor were weakly related to the frequency of wave participation. However, the factor that was very strongly, positively related to the frequency of wave participation was the Structure factor.

The best way of testing attrition bias in twin studies is to see whether heritability is expected to be related to the tendency to participate. A calculation of the average twin correlations over the Big Five HIPIC scales for all informants showed a MZ/DZ ratio of .55/ .20 for those participating in one wave, $.59 / .12$ for those participating in two waves and $.59 / .18$ for those participating in three waves. Attrition does not seem to have much influence on the expected heritability estimates.

\section{Attrition from Waves to Interview}

All twins were invited to a face-to-face interview at age 18, and 1210 pairs who had participated in any wave accepted the invitation, whereas 328 pairs declined. In addition, 215 pairs who had never participated in any waves accepted to be interviewed. Table 4 shows the sex-zygosity combinations among those who declined to be interviewed in spite of participation in at least one wave, those who participated in both wave and interview and those who only participated in the interview. There were small and nonsignificant differences between those who were interviewed plus wave and those who were interviewed only. However, there were strikingly different sex-zygosity combinations $\left(\chi^{2}=14.350, d f=5, p=.014\right)$ among pairs participating in wave plus interview compared to those participating in wave but declining the interview. Those refusing the interview were more often male, irrespective of zygosity, and more often from opposite-sex twin pairs.

The twins' average age at the time of the interview was 19.1 years, ranging from 17.5 to 23.3 years. Sixty-two percent of the interviewees were 18 years, $18 \%$ were 19 years, $9 \%$ were 20 years, $7 \%$ were 21 years and finally, $4 \%$ were $22-23$ years.

Consent to the interview was related to the personality factors mentioned above. The Structure factor, consisting of the HIPIC Big Five conscientiousness and openness (imagination) scales, good school habits and resilience, predicted participation in the interview, whereas the Shyness and the Conduct Problems factors did not.

To see the total picture of predictors of participation in the interview, a stepwise logistic regression analysis was conducted. In addition to the personality factor, birth year (cohort), zygosity, sex and number of times the twins had participated in the study were included. It turned out that zygosity did not predict consenting to the interview. Female sex (Wald $=29.06, p=.000$ ), cohort (later cohort implied shorter time in the project before the interview; Wald $=48.01, p=.000$ ) and participation in higher number of waves before or after the interview (Wald $=176.96, p=.000$ ) predicted consent to the interview. Including all these variables, the Structure factor still predicted participation (Wald $=4.03, p=.045$ ).

As mentioned earlier, the most important test of attrition bias is to compare the available twin correlations for participation and nonparticipation in specific parts of the study. Regarding participation versus nonparticipation in the interview among those participating in any wave, the MZ/DZ correlations of the Big Five HIPIC scales across waves and informants were .59/.17 versus .61/.26. Thus, there does not seem to be any difference in expected personality heritability between those consenting and those not consenting to the interview.

Regarding the twins who had not responded to the waves but came to the interview, they were more often from the younger cohorts and thus consented to the project and interview at a younger age. It may be that they were too young to follow through when they received the questionnaires or that an interview was more attractive. They had slightly higher scores on borderline, antisocial, paranoid and dependent personality disorder traits. Logistic stepwise 
Table 4. Number (\%) of twin pairs participated in the waves of questionnaire data collection and/or interview by sex and zygosity

\begin{tabular}{|c|c|c|c|c|c|c|c|c|c|c|c|c|}
\hline & \multicolumn{2}{|c|}{ MMZ } & \multicolumn{2}{|c|}{ FMZ } & \multicolumn{2}{|c|}{ MDZ } & \multicolumn{2}{|c|}{ FDZ } & \multicolumn{2}{|c|}{ ODZ } & \multicolumn{2}{|c|}{ SUM } \\
\hline & $n$ & $\%$ & $n$ & $\%$ & $n$ & $\%$ & $n$ & $\%$ & $n$ & $\%$ & $n$ & $\%$ \\
\hline At least one wave, no interview & 64 & 19.5 & 46 & 19.5 & 64 & 19.5 & 45 & 13.7 & 109 & 33.2 & 328 & 100.0 \\
\hline At least one wave and interview & 166 & 13.7 & 297 & 13.7 & 161 & 13.3 & 237 & 19.6 & 349 & 28.8 & 1210 & 100.0 \\
\hline Interview only & 31 & 14.4 & 52 & 14.4 & 27 & 12.6 & 32 & 14.9 & 73 & 34.0 & 215 & 100.0 \\
\hline Total number interviewed & 197 & 13.8 & 349 & 13.8 & 188 & 13.2 & 269 & 18.9 & 422 & 29.6 & 1755 & 100.0 \\
\hline
\end{tabular}

Note: $M M Z$ = male monozygotic, FMZ = female monozygotic, MDZ = male dizygotic, FDZ = female dizygotic, ODZ = opposite-sex dizygotic.

regression analysis showed that only borderline traits (Wald 14.546, $p=.000$ ), in addition to younger age at consent (Wald 21.143, $p=.000$ ), independently significantly predicted participation.

\section{Conclusion}

The Oslo University Twin sample presented in this article was developed with the aim of investigating the causes and consequences of resilience in youth and adolescence. Because of the combination of informants (parents and twins), the combination of questionnaires and face-to-face diagnostic interview, the high number of assessments repeated biannually and the broad coverage of personality, vulnerability, mental disorders, traumas and other environmental factors, there is a vast number of varied research questions that can be addressed.

Representativeness was also good. In this small country with good registries, it was possible to trace almost all twins from younger cohorts (12-18 years old). More than half of the traced twins (53.3\%) consented to participate in the study. Furthermore, $61.9 \%$ of these actually participated in at least one of the three biannual waves. In the interview, $57.3 \%$ of those who consented to the project participated. Of these, $85.1 \%$ had also participated in any waves. The likelihood to participate in a higher number of waves as well as interview was related to structured personality, female sex, but not to zygosity. Most importantly, however, attrition did not bias the heritability estimates.

\section{References}

Antonovsky, A. (1987). Unravelling the mystery of health: How people manage stress and stay well. San Francisco,CA: Jossey-Bass.

Birmaher, B., Khetarpal, S., Brent, D., Cully, M., Balach, L., Kaufman, J., \& Neer, S. M. (1997). The Screen for Child Anxiety Related Emotional Disorders (SCARED): Scale construction and psychometric characteristics. Journal of the American Academy of Child \& Adolescent Psychiatry, 36, 545-553.

Block, J., \& Kremen, A. M. (1996). IQ and ego-resiliency: Conceptual and empirical connections and separatenes. Journal of Personality and Social Psychology, 70, 349-361.

California Department of Education. (2003). California Healthy Kids Survey, High School Questionnaire, Module B: Resilience and Youth Development. http://instruction.esuhsd.org/chks

Cantril, H. (1965). The pattern of human concerns. New York, NY: New Brunswick.

Costa, P. T., \& McCrae, R. R. (1992). NEO PI-R. Professional manual. Odessa, FL: Psychological Assessment Resources.

Donovan, J. E., \& Jessor, R. (1985). Structure of problem behavior in adolescence and young adulthood. Journal of Consulting and Clinical Psychology, $53,890-904$.

Fendrich, M., Weissmann, M. M., \& Warner, V. (1990). Screening for depressive disorder in children and adolescents: Validating the Center for
Epidemiological Studies Depression Scale for Children. Americal Journal of Epidemiology, 131, 538-551.

Fink, L. A., Bernstein, D., Handelsman, L., Foote, J., \& Lovejoy, M. (1995). Initial reliability and validity of the childhood trauma interview: A new multidimensional measure of childhood interpersonal trauma. American Journal of Psychiatry, 152, 1329-1335.

Garber, J., Walker, L. S., \& Zeman, J. (1991). Somatization symptoms in a community sample of children and adolescents: Further validation of the Children's Somatization Inventory. Psychological Assessment: A Journal of Consulting and Clinical Psychology, 3, 588-595.

Garner, D., \& Olmstedt, M. (1984). Manual for Eating Disorder Inventory (EDI). Odessa, FL: Psychological Resources.

Goodman, R. (1997). The strengths and difficulties questionnaire: A research note. Journal of Child Psychology, Psychiatry, and Allied Disciplines, 38, 581-586.

Goodman, R. (2001). Psychometric properties of the strengths and difficulties questionnaire. Journal of the American Academy of Child \& Adolescent Psychiatry, 40, 1337-1345.

Heath, A. C., Madden, P. A. F., Grant, J. D., McLaughlin, T. D., Todorov, A. A., \& Bucholz, K. K. (1999). Resiliency factors protecting against teenage alcohol use and smoking: Influences of religion, religious involvement and values, and ethnicity in the Missouri Adolescent Female Twin Study. Twin Research, 2, 145-155.

Helgeland, M. I., Kjelsberg, E., \& Torgersen, S. (2005). Continuities between emotional and disruptive behavior disorders in adolescence and personality disorders in adulthood. Journal of Psychiatry, 162, 1941-1947.

Helgeland M. I., \& Torgersen S. (2004). Developmental antecedents of borderline personality disorders. Comprehensive Psychiatry, 45, 138-147.

Johnston, L. D., O’Malley, P. M., Bachman, J. G., \& Schulenberg, J. E. (2005). Monitoring the Future national results on adolescent drug use: Overview of key findings, 2004 (Rep. No. NIH Publication No. 05-5726). Bethesda, MD: National Institute on Drug Abuse.

Knight, J. R., Sherritt, L., Shrier, L. A., Harris, S. K., \& Chang, G. (2002). Validity of the CRAFFT substance abuse screening test among adolescent clinic patients. Archives of Pediatrics \& Adolescent Medicine, 156, 607-614.

LeBlanc, M., \& Tremblay, R. E. (1988). A study of factors associated with the stability of hidden delinquency. International Journal of Adolescence and Youth, 1, 269-291.

Lecruiber, Y., Sheehan, D., Weiller, E., Amorim, P., Bonora, I., Harnett Sheehan, K., \& Dunbar, G. (1997). The Mini International Neuropsychiatric Interview (MINI): A short diagnostic structured interview: Reliability and validity according to CIDI. European Psychiatry, 12, 224-231.

Lenswelt-Mulders, G., \& Hettema, J. (2001). Analysis of genetic influence on the consistency and variability of the Big Five across different stressful situations. European Journal of Personality, 15, 355-371.

Martinsen, Ø. L., Nordvik, H., \& Østbø, L. E. (2005). Norske versjoner av NEO PI-R og NEO FFI. [Norwegian versions of NEO PI-R and NEO FFI]. Tidsskrift for Norsk Psykologforening [Journal of the Norwegian Psychology Association], 42, 421-423.

Masten, A. S., Neemann, J., \& Andenas, S. (1994). Life events and adjustment in adolescents: The significance of event independence, desirability, and chronicity. Journal of Research on Adolescence, 4, 71-97. 
Mehlum, L. (1998). Suicidal ideation and sense of coherence in male conscripts. Acta Psychiatrica Scandinavica, 98, 487-492.

Mervielde, I., \& De Fruyt, F. (1999). Construction of the Hierarchical Personality Inventory for Children (HiPIC). In I. Mervielde, I. Deary, F. De Fruyt, \& F. Ostendorf (Eds.), Personality psychology in Europe (pp. 107-127). Tilburg, Netherlands: Tilburg University Press.

Pastorelli, C., Caprara, G. V., Barbanelli, C., Rola, J., Rozsa, S., \& Bandura, A. (2001). The structure of children's perceived self-efficacy: A cross-national study. European Journal of Psychological Assessment, 17, 87-97.

Patrick, C. J., Curtin, J. C., \& Tellegen, A. (2002). Development and validation of a brief form of the Multidimensional Personality Questionnaire. Psychological Assessment, 14, 150-163.

Petersen, A. C., Crockett, L., Richards, M., \& Boxer, A. (1988). A self-report measure of pubertal status: Reliability, validity, and initial norms. Journal of Youth and Adolescence, 17, 117-133.

Pfohl, B., Blum, N., \& Zimmerman, M. (1997). Structured interview for DSMIV personality (SIDP-IV). Washington, DC: American Psychiatric Press.

Radloff, L. (1977). The CES-D scale: A self-report depression scale for research in the general population. Applied Psychological Measurement, 1, 385-401.

Reitman, D., Currier, R. O., Hupp, S. D., Rhode, P. C., Murphy, M. A., \& O'Callaghan, P. M. (2001). Psychometric characteristics of the Parenting Scale in a Head Start population. Journal of Clinical Child Psychology, 30, 514-524.
Russel, D., Peplau, L. A., \& Cutrona, C. E. (1980). The revised UCLA Loneliness Scale: Concurrent and discriminant validity evidence. Journal of Personality and Social Psychology, 39, 472-480.

Sheehan, D., Lecruiber, Y., Sheehan, K., Amorim, P., Janavs, J., Weiller, E., .. Dunbar, G. C. (1998). The Mini-International Neuropsychiatric Interview (M.I.N.I.): The development and validation of a structured diagnostic psychiatric interview for DSM-IV and ICD-10. Journal of Clinical Psychiatry, 59, S22-S33.

Sheehan, D., Lecruiber, Y., Sheehan, K., Janavs, J., Weiller, E., Keskiner, A., .. Dunbar, G. C. (1997). The validity of the Mini International Neuropsychiatric Interview (MINI) according to the SCID-P and its reliability. European Psychiatry, 12, 232-241.

Spirito, A., Stark, L., \& Williams, C. (1988). Development of a brief coping checklist for use with pediatric populations. Journal of Pediatric Psychology, 13, 555-574.

Torgersen, S. (1979). The determination of twin zygosity by means of a mailed questionnaire. Acta Geneticae Gemellologicae, 28, 225-236.

Torgersen, S., Kringlen, E., \& Cramer, V. (2001). The prevalence of personality disorders in a community sample. Archives of General Psychiatry, 58, 590-596.

Tremblay, R. E., Phil, R. O., Vitaro, F., \& Dobkin, P. L. (1994). Predicting early onset of male antisocial behavior from preschool behavior. Archives of General Psychiatry, 51, 732-739.

Wagnild, G. M., \& Young, H. M. (1993). Development and psychometric evaluation of the resilience scale. Journal of Nursing Measurement, 1, 165-178. 